\title{
Clinical Attributes of Pedophilia-A Mental Illness and Psychopharmacological Approaches to Hit Pedophiles
}

\author{
Nabiha Khalid ${ }^{1 *}$ and Quratulain Yousaf ${ }^{2}$ \\ ${ }^{1}$ Department of Biochemistry and Molecular Biology, University of Gujrat, Sialkot Campus, Pakistan \\ ${ }^{2}$ Department of Biochemistry and Molecular Biology, University of Gujrat, Pakistan
}

"Corresponding author: Nabiha Khalid, Department of Biochemistry and Molecular Biology, University of Gujrat, Sialkot Campus, Pakistan, Tel: +92-0302-5419079; Email: nabihatufail@gmail.com

Rec date: March 13, 2018; Acc date: March 20, 2018; Pub date: March 28, 2018

Copyright: @ 2018 Khalid N, et al. This is an open-access article distributed under the terms of the Creative Commons Attribution License, which permits unrestricted use, distribution, and reproduction in any medium, provided the original author and source are credited.

\begin{abstract}
Pedophilia is a mental ataxia and psychotic anarchy associated with more sexual interest in prepubescent children. Pedophiles have impaired frontal lobes, hippocampus and amygdala linked with cognitive defects, antisocial and violent behaviour. These pedophiles have abnormal level of testosterone production that causes the sexual urgency in them. Besides psychotherapies, several drugs and pharmacological approaches have been designed for the treatment of pedophiles. Sexual assault and child molestation by these pedophiles is one of the current issue and every country is the victim of these pedophiles and different cases have been reported worldwide as well as in Pakistan. This paper highlights the basic aspects of pedophiles, their mental state, clinical features and different initiatives taken by policymakers to control child abuse.
\end{abstract}

Keywords: Pedophilia; Mental illness; Cognitive impairment; Testosterone

\section{Introduction}

Pedophilia is a psychiatric disorder characterized by intensive sexual arousal and behavioural changes that are related with increased sexual activity with a child. Studies suggested that pedophiles have frontal abnormalities and defective cognitive functioning, but the biological basis of this disorder is still unmarked [1]. Pedophiles innervate to disguise their feelings and thoughts and show sexual attraction towards children. New developments and studies suggested that pedophiles have strong association between children and sex while nonpedophiles have an association between adults and sex [2].

Pedophiles have impaired prefrontal cortex, hippocampus and amygdala associated with behavioural changes in the body. Besides these, pedophiles have less active frontal lobes with antisocial and aggressive behaviour. Studies indicated that in some pedophiles frontal temporal dysfunction cause sexual urges and poorly inhibited thoughts regarding sexual behaviour [1]. Compulsive sexual behaviour is often linked with the pedophiles in which excessive sexual cognitive behaviour occur that led to the child abuse [3].

Some studies indicated that pedophiles have higher level of testosterone as compared to normal men. Impaired brain functioning causes the release of GnRH that ultimately cause the abnormal amount of testosterone in pedophiles and more sexual urgency in these pedophiles. Mostly, pedophiles are treated with psychological therapies but different antihormonal therapies are available to control the level of testosterone in pedophiles in extreme cases [4].

Sexual Child Abuse done by pedophiles has become one of the swinging issue for every country. Several cases have been reported globally and different countries have made some initiatives to fight with these pedophiles. Professional training, school-based education and offender management programs have been designed to educate children about child abuse and treat pedophiles [5].

\section{Pedophilia-A Psychiatric Disorder}

Pedophilia is a condition in which individual sexual behaviour and attraction increased towards pre-pubertal children. It is an act of sexual activity with the children of age 13 or less than 13 . The person who do this act known as 'pedophile' and mostly are men and can be attracted towards both sexes male and female. Pedophiles mostly showed off themselves as friends and relatives. These pedophiles gazing at children, undressing them or touched them at their private organs [6-8].

\section{Mental Illness of Pedophiles}

Studies suggested that pedophiles have behavioural dysfunction, frontal abnormalities and defective cognitive functions. Arousal of Human sexual behaviour is a psychological and physiological phenomenon. Different imaging techniques such as magnetic resonance imaging (MRI) and Positron emission tomography (PET) indicated that pedophiles have defective frontal lobes, hippocampus that controls behavioural changes, amygdala and ganglia. Due to this these pedophiles show violent, antisocial and psychopathic behaviour [7].

Pedophilia causing the brain disease and dysfunction of sexual disorder results in inappropriate sexual interest. Pedophilia present in child sexual criminal's due to their late development of sexual behaviour [9]. In case, when non-pedophiles having the sexual attraction towards adults but show the sexual behaviour to children, manifest the pedophilic behaviour. These non-pedophiles manifest the sexual behaviour towards children along with a brain disease. The behaviour of pedophiles can be the manifestation of neurological disorder [10]. 
Although, abnormal sexual behaviour is usually seen in brain disorders like dementia and other [11]. But investigators and clinicians cannot recognize how these patients show the inappropriate sexual behaviour towards children. There is much less studies on the neurobiology of pedophilia and people having the pedophilia behaviour without the disorder of pedophilia. Studies of the pathophysiology and mechanisms of the patients having pedophilic behaviour with brain disorder can show the nature of pedophilia and will develop active, targeted intrusions for the egregious behaviour [12]. In fact, pedophilia behaviour may occurs due to brain disease result in enhanced hypersexual and disinhibited actions in the people having a disposition to sexual desirability to children. inappropriate sexual behaviour resulted from neurological disorders cause affect the amygdalae frontal lobe, non-motor basal ganglia, anterior temporal lobes and hypothalamus, or septal nuclei [7].

\section{Behavioural Changes and Eye Movements of Pedophiles}

Behaviour of pedophiles can be associated with the reduced anxiety or fear for the nature of their behaviour, sexual preoccupation, disinhibited behaviour and poor impulse control with true hypersexuality. The onset of paedophilic behaviour may be due to disorders which are disturbing the right anterior temporal-amygdala and right orbitofrontal cortex but marked hypersexuality from subcortical dysfunction can also release pedophilic sexual interests in those predisposed to this paraphilic orientation. Future research on the brain mechanisms of pedophilic behaviour can employ developing neuroid- aging and neurophysiological techniques to further isolate the underlying brain mechanisms [13].

Eye movements are necessary to attract viewer's attention and this attention plays significant role in sexual arousal. Eye tracking is the ability to capture complex scenes. Normally, for the perception of scene eye movements of humans is divided into two categories: fixations and saccades. Fixations a time in which eye does not move and attract attention while saccades are voluntary eye movements and by this way acquisition of information not take place in saccades. Fixating is a way to gain attention and attract someone. In pedophiles, loss of mental health cause more fixations instead of saccades due to this these pedophiles visually attract children and sexual arousal more in them. Influence of hormones especially testosterone level in males has pronounced effect on longer time eye interaction [14].

\section{Level of Testosterone in Pedophiles}

Studies demonstrated that sexual arousal, motivation and behavioural changes are dependent on male hormone testosterone in men. It is reported that if GnRH antagonist is administered in males' level of testosterone would decreases with less sexual desire. Mostly, Pedohphiles are characterized by the increased level of testosterone that causes sexual fantasy and more attraction to children [15]. Gonadotropin Releasing Hormone is releases by the hypothalamus that acts on anterior pituitary gland to cause the release of LH and FSH. These two hormones act on the testes in males and cause spermatogenesis and sexual fantasy. The level of this hormone is abnormal in pedophiles [16].

\section{Pharmacological Therapy for Pedophiles}

Antihormonal Therapy is always initiated when psychotherapy for pedophiles do not show any improvement. Two categories of drugs used for the treatment of pedophiles, GnRH antagonists and antiandrogens. Antiandrogens includes the cyproterone acetate (CPA) and medroxyprogesterone (MPA). Antiandrogens and GnRH agonists decreases the sexual fantasy in pedophiles. CPA drug decreases sexual arousal by two ways: On the one hand, it acts as antiandrogen and binds with the testosterone receptors as a result production of testosterone cesses. On the other hand, CPA decreases the secretion of $\mathrm{GnRH}$ from hypothalamus as a result, LH synthesis and release cesses from anterior Pituitary gland and ultimately level of testosterone decreases in pedophiles. It is reported that $80 \%$ patients show less sexual behaviour and sexual fantasies within one month by using this drug. Side effects of this drug are liver toxicity, depressive mood and inhibition of spermatogenesis (Figure 1) [15].

Medroxyprogesterone (MPA) is also an antiandrogen drug. This drug inhibits the gonadotropin secretion from hypothalamus and ultimately reduces the production of testosterone in the testes. This is an orally administrated drug or may administered through injection after every 03 months. Side effects of this drug are depression, fluid retention, weight gain and inhibition of spermatogenesis [17].

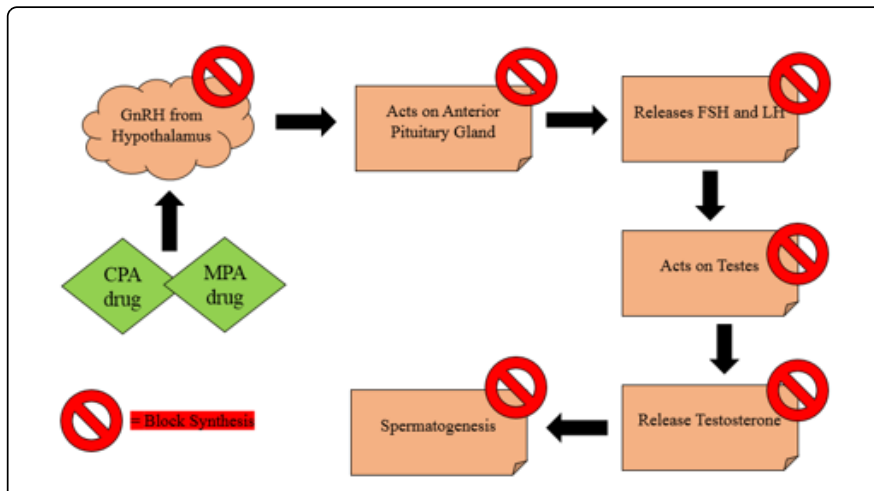

Figure 1: Action of drugs in the inhibition of spermatogenesis in pedophiles.

\section{Psychological Therapies for Pedophiles}

Psychological therapies proven effective for the treatment of pedophiles. These therapies motivated the sex offenders to change themselves. Studies indicated that goals of these psychotherapies are: moving the pedophiles to admit to his sexual preference with the children. To help the pedophiles to see the children as his victim not a partner and Overcoming revolutionizations about his own motives for sexual involvement with children (Table 1) [18].

\begin{tabular}{|l|l|l|}
\hline S No. & Therapy & Therapy Action \\
\hline 1 & Group Therapy & Sex offenders re-examine their hidden motives \\
\hline 2 & Imagery Technique & $\begin{array}{l}\text { Altering deviant behaviour by Sexual responses } \\
\text { are imagined }\end{array}$ \\
\hline 3 & Graphic Portrayals & Thought provoking therapy for offender \\
\hline 4 & $\begin{array}{l}\text { Cognitive } \\
\text { Behaviour therapy } \\
\text { (CBT) }\end{array}$ & Learning and cognitive improvement \\
\hline
\end{tabular}

Table 1: Psychological Therapies for the treatment of pedophiles. 
Page 3 of 4

\section{Child Abuse Cases Reported in Pakistan}

Pakistan is one of the victim country of these molesters and many cases of child abuse has been reported in recent past. Recently, a brutal rape reported of an innocent girl Zainab in Kasur. According to report, in 2014 rape reported of 12 young girls all between 5-8 years old and then their dead bodies recovered from different parts of the Kasur city.

Study indicated that from 2010-2017, 22,528 cases of child abuse has been reported and this number is increasing day by day. In the year of 2010, 2,252 cases reported, in 2011,2,303 cases reported of child abuse, in 2012, 2,788 cases, in 2013 the number continues increased up to 3002 , in 2014, 3508 cases reported, in 2015 3,768, in 2016, 4,139 cases while in the first six months of 2017, 768 cases of child abuse have been reported in different cities of Pakistan (Figure 2). Globally, India is in the top of the list in the sexual child abuse cases reported by National Crime Record Bureau. In India after every 15 minutes one child is sexually harassed [19].

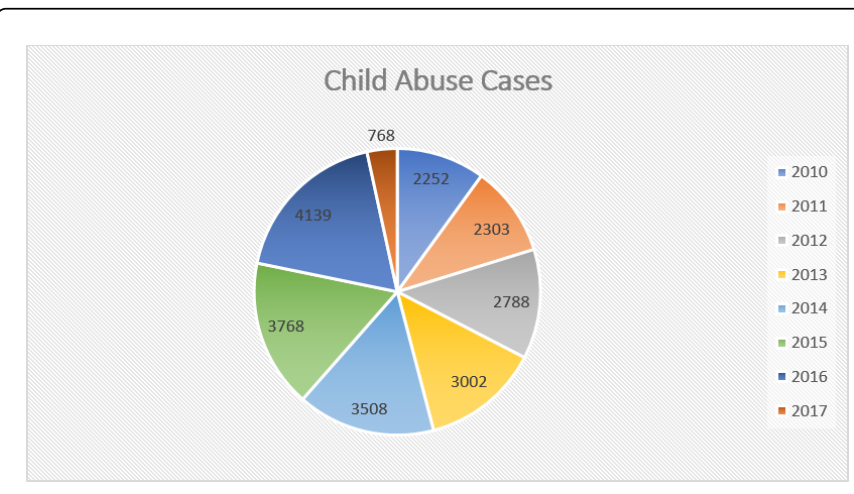

Figure 2: Child Abuse cases reported in Pakistan.

\section{Time to Act}

To control child abuse and to safe children from these sexual offenders there is a time to control this crime act. Professional training programs and Social Education programs should be started in every country to control this act. The purpose of these programs is to improves the attitudes of pedophiles and give knowledge to children about sexual behaviour [20].

Offender Management Initiative has been taken by different societies to combat with pedophiles. This initiative includes notifying community about their presence, registering sex offenders and imposing longer prison punishments for them. Policy makers has suggested this initiative has helped to control child sexual abuse. Another initiative has taken by many countries is school-based educational programs to teach children such skills as how to identify extreme situations, to refuse offender's approach. These programs have achieved certain of their goals. Different counselling strategies should be adopted by government to tackle these offenders and to prevent negative mental health [21].

\section{Conclusion}

Sexual attraction and sexual assault towards children is now become a global issue and many cases reported throughout worldwide. Pedophiles diagnose with mental illness and high level of male hormone testosterone. These pedophiles shows deviant and antisocial behaviour towards the society. Different contributing factors are responsible for their aggressive nature. Pedophilic behaviour is unethical and demands the awareness, education and training for society.

\section{References}

1. Schiffer B, Krueger T, Paul T, De Greiff A, Forsting M, et al. (2008) Brain response to visual sexual stimuli in homosexual pedophiles. Journal of Psychiatry \& Neuroscience: JPN 33: 23.

2. Gray NS, Brown AS, MacCulloch MJ, Smith J, Snowden RJ (2005) An implicit test of the associations between children and sex in pedophiles. Journal of Abnormal Psychology 114: 304.

3. Kuzma JM, Black DW (2008) Epidemiology, prevalence, and natural history of compulsive sexual behavior. Psychiatric Clinics 31: 603-611.

4. Jordan K, Fromberger P, Stolpmann G, Müller JL (2011) The role of testosterone in sexuality and paraphilia-A neurobiological approach. Part II: Testosterone and paraphilia. The Journal of Sexual Medicine 8: 3008-3029.

5. Jahnke S, Philipp K, Hoyer J (2015) Stigmatizing attitudes towards people with pedophilia and their malleability among psychotherapists in training. Child Abuse \& Neglect 40: 93-102.

6. Green R (2002) Is pedophilia a mental disorder? Archives of Sexual Behavior 31: 467-471.

7. Mendez MF, Chow T, Ringman J, Twitchell G, Hinkin CH (2000) Pedophilia and temporal lobe disturbances. The Journal of Neuropsychiatry and Clinical Neurosciences 12: 71-76.

8. Seto MC (2012) Is pedophilia a sexual orientation?. Archives of Sexual Behavior 41: 231-236.

9. Tost H, Vollmert C, Brassen S, Schmitt A, Dressing H, et al. (2004) Pedophilia: neuropsychological evidence encouraging a brain network perspective. Medical Hypotheses 63: 528-531.

10. Cantor JM, Blanchard R, Christensen BK, Dickey R, Klassen PE, et al. (2004) Intelligence, memory, and handedness in pedophilia. Neuropsychology 18: 3 .

11. Mendez MF (2010) The unique predisposition to criminal violations in frontotemporal dementia. The Journal of the American Academy of Psychiatry and the Law 38: 318.

12. Burns JM, Swerdlow RH (2003) Right orbitofrontal tumor with pedophilia symptom and constructional apraxia sign. Archives of Neurology 60: 437-440.

13. Rosman SV (2017) Pedophilia in the Context of Entropy Neuron Glial Networks of the Brain. Mental Health (PPhT) 15: 4-1.

14. Fromberger P, Jordan K, Von Herder J, Steinkrauss H, Nemetschek R, et al. (2012) Initial orienting towards sexually relevant stimuli: Preliminary evidence from eye movement measures. Archives of Sexual Behavior 41: 919-928.

15. Stoléru S (2008) The brain, androgens, and pedophilia. In Hormones and Social Behaviour. Springer, Berlin, Heidelberg, pp: 163-175.

16. Pfaff DW, Kordon C, Chanson P (2008) Hormones and social behavior Springer Science \& Business Media.

17. Schober JM, Kuhn PJ, Kovacs PG, Earle JH, Byrne PM, et al. (2005) Leuprolide acetate suppresses pedophilic urges and arousability. Archives of Sexual Behavior 34: 691-705.

18. Murray JB (2000) Psychological profile of pedophiles and child molesters. The Journal of Psychology 134: 211-224.

19. Mangat $\mathrm{R}$ (2018) Child abuse talk still a taboo in Pakistan.

20. Abbey A, Zawacki T, Buck PO, Clinton AM, McAuslan P (2004) Sexual assault and alcohol consumption: What do we know about their relationship and what types of research are still needed?. Aggression and Violent Behavior 9: 271-303.

21. Finkelhor D (2009) The prevention of childhood sexual abuse. The Future of Children 19: 169-194. 
Citation: Khalid N, Yousaf Q (2018) Clinical Attributes of Pedophilia-A Mental Illness and Psychopharmacological Approaches to Hit Pedophiles. Clin Med Biochem 4: 141. doi:10.4172/2471-2663.1000141 